\title{
Schottky-Barrier Height Lowering by an Increase of the Substrate Doping in PtSi Schottky Barrier Source/Drain FETs
}

\author{
G. P. Lousberg, H. Y. Yu, B. Froment, E. Augendre, A. De Keersgieter, A. Lauwers, \\ M.-F. Li, P. Absil, M. Jurczak, and S. Biesemans
}

\begin{abstract}
In this letter, the Schottky-barrier height (SBH) lowering in Pt silicide/n-Si junctions and its implications to Schottkybarrier source/drain p-field-effect transistors (p-SBFETs) are studied experimentally and numerically. We demonstrate that the increase of the n-Si substrate doping is responsible for a larger hole SBH lowering through an image-force mechanism, which leads to a substantial gain of the drive current in the long-channel bulk p-SBFETs. Numerical simulations show that the channel doping concentration is also critical for short-channel p/n-silicon-on-insulator SBFET performance.
\end{abstract}

Index Terms-PtSi ${ }_{x}$, Schottky-barrier (SB) lowering, Schottkybarrier source/drain field-effect transistors (SBFETs).

\section{INTRODUCTION}

$\mathbf{S}$ CHOTTKY-barrier source/drain (S/D) field-effect transistors (SBFETs) are promising substitutes for conventional doped S/D MOSFETs for sub-22-nm CMOS technology since silicide $\mathrm{S} / \mathrm{D}$ can provide abrupt junctions with low series resistance [1]-[4]. $\mathrm{PtSi} / \mathrm{YbSi}_{1+x}$ are considered to be among the best silicide materials for $\mathrm{p}$-/n-SBFET application, but their relative low hole/electron Schottky barrier height $(\mathrm{SBH})$ of $\sim 220 \mathrm{meV}$ still limits drastically the drive current [2]-[4]. To make the SBFETs comparable to state-of-the-art short-channel MOSFETs in terms of drivability, the intrinsic SBH should be lowered to $\sim 100 \mathrm{meV}$ [3]. Recently, it has been shown that the effective electron SBH could be lowered by inserting a thin insulator [3] or a highly doped layer (defined with a dopant segregation technique [5], [6]) at the silicide/Si junction. To our knowledge, no such method has already been reported for hole SBH. In this letter, we demonstrate experimentally and numerically that increasing the $\mathrm{n}-\mathrm{Si}$ substrate doping could lower the hole SBH of PtSi/n-Si junctions through an imageforce mechanism [7], which leads to a substantial gain of the drive current in the long-channel bulk p-SBFETs. Numerical

Manuscript received September 2, 2006; revised November 8, 2006. The review of this letter was arranged by Editor C. Bulucea.

G. P. Lousberg was with the Interuniversity Microelectronics Center, 3001 Leuven, Belgium. He is now with the Faculty of Applied Sciences, University of Liege, 4000 Liege, Belgium.

H. Y. Yu, E. Augendre, A. De Keersgieter, A. Lauwers, P. Absil, M. Jurczak, and S. Biesemans are with the Interuniversity Microelectronics Center, 3001 Leuven, Belgium (e-mail: hongyu@imec.be).

B. Froment is an STMicroelectronics assignee with the Interuniversity Microelectronics Center, 3001 Leuven, Belgium.

M.-F. Li is with the Department of Microelectronics, Fudan University, Shanghai 201203, China

Digital Object Identifier 10.1109/LED.2006.889045 simulations predict that the channel doping is also critical for short-channel silicon-on-insulator (SOI) SBFET performance improvement. SBH lowering method proposed in this letter only relies on the conventional CMOS process techniques such as well ion implantation (I/I) and is thus very promising for future SBFET development.

\section{DEVICE FABRICATION}

The p-SBFETs $(W / L=1 \mu \mathrm{m} / 1 \mu \mathrm{m})$ were fabricated on 8 -in wafers. Only the bottom part of the wafer received the well I/I: either P $\left(3 \mathrm{e} 12 \mathrm{~cm}^{-2}, 120 \mathrm{keV}\right)$ or $\mathrm{P}\left(3 \mathrm{e} 12 \mathrm{~cm}^{-2}, 120 \mathrm{keV}\right)$ + As $\left(1 \mathrm{e} 12 \mathrm{~cm}^{-2}, 90 \mathrm{keV}\right)$. In the following text, the bottom part is referred to as the south well, whereas the top part is referred to as the north well. Capacitance-voltage $(C-V)$ measurements of MOS capacitors (data not shown) indicate a substrate doping level of $1 \mathrm{e} 16 \mathrm{~cm}^{-3}$ in the north well and of $8 \mathrm{e} 16$ or $2 \mathrm{e} 17 \mathrm{~cm}^{-3}$ in the south well, respectively, with $\mathrm{P}$ or $\mathrm{P}+\mathrm{As} \mathrm{I} / \mathrm{I}$. The gate stack is made of poly-Si and $\mathrm{SiON}$, with an equivalent oxide thickness of $\sim 2 \mathrm{~nm}$. Twenty-five nanometers of $\mathrm{Pt}$ was deposited on the substrate and thermally annealed at $550{ }^{\circ} \mathrm{C}$ (for $1 \mathrm{~min}$ ) for the silicidation process. After a selective etching of the unreacted metal, the depth of PtSi S/D is $\sim 50 \mathrm{~nm}$, as measured by cross-sectional scanning electron microscope (XSEM; data not shown). Ultraslim ( $11 \mathrm{~nm}) \mathrm{SiN}$ spacers were used such that $\mathrm{S} / \mathrm{D}$ silicide reaches the gate edge due to a lateral diffusion of the PtSi under the spacers, which is crucial for the electrical performance improvement [8]. Note that the poly$\mathrm{Si}$ electrode was activated before PtSi formation. Before the fab out of the devices, a forming gas annealing at $420{ }^{\circ} \mathrm{C}$ for 20 min was also applied.

\section{RESUlTS AND Discussion}

\section{A. SBH Measurement}

We measured the electron $\mathrm{SBH}\left(\phi_{e}\right)$ of $\mathrm{PtSi} / \mathrm{n}-\mathrm{Si}$ diodes fabricated on the same substrates as the SBFETs. Considering the possible high series resistance, we extracted $\phi_{e}$ from the forward current-voltage $(I-V)$ characteristics using the Norde method [9]. A set of extracted electron $\mathrm{SBH}$ of $\mathrm{PtSi} / \mathrm{n}-\mathrm{Si}$ diodes is plotted in Fig. 1. SB diodes were measured in a statistical manner; i.e., they lie on a north-to-south straight line in the wafer. The electron SBH distribution of the diodes located in the north well is very tight and has an average value close to $870 \mathrm{meV}$, which is consistent with the already reported values 


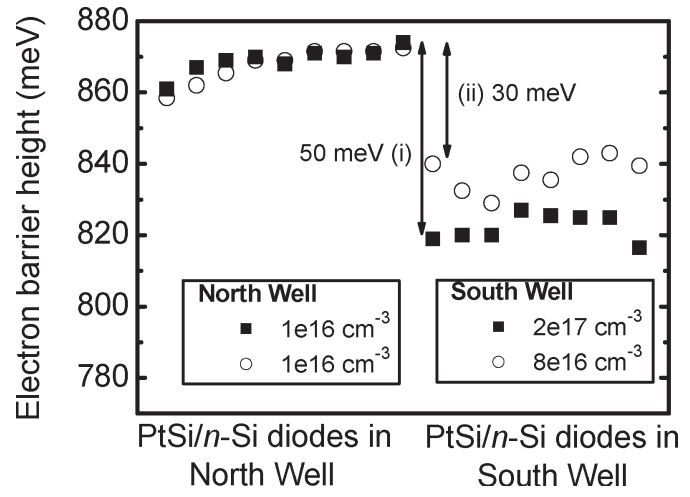

Fig. 1. Electron barrier heights extracted with Norde method of PtSi/n-Si diodes located on a straight line in the wafer. The n-type bulk Si substrate has a dopant concentration of $1 \mathrm{e} 16 \mathrm{~cm}^{-3}$ (north well), $8 \mathrm{e} 16 \mathrm{~cm}^{-3}$ (circle in south well), and $2 \mathrm{e}^{2} 7 \mathrm{~cm}^{-3}$ (square in south well).

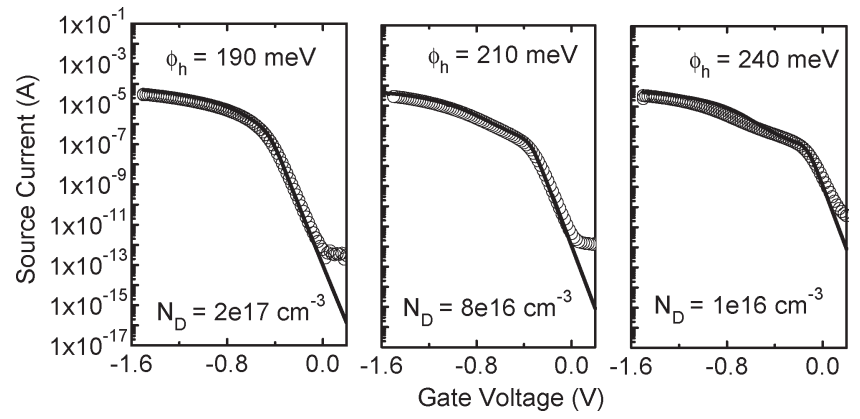

Fig. 2. Experimental (circles) and simulated (solid lines) $I_{s}-V_{g}$ of $1-\mu \mathrm{m}$ channel length p-SBFET with channel doping of (a) $2 \mathrm{e} 17 \mathrm{~cm}^{-3}$, (b) $8 \mathrm{e} 16 \mathrm{~cm}^{-3}$, and (c) $1 \mathrm{e} 16 \mathrm{~cm}^{-3}$. The hole barrier heights are 190,210 , and $240 \mathrm{meV}$, respectively, for doping concentrations of $2 \mathrm{e} 17,8 \mathrm{e} 16$, and $1 \mathrm{e} 16 \mathrm{~cm}^{-3} \cdot V_{d}=-1.1 \mathrm{~V}$.

[1]-[3]. In the south well, the values of the SBH are a function of the doping concentration: The average value is around $840 \mathrm{meV}$ for the $8 \mathrm{e} 16 \mathrm{~cm}^{-3}$ doped substrate and $820 \mathrm{meV}$ when the doping concentration is $2 \mathrm{e} 17 \mathrm{~cm}^{-3}$. Note that the extracted SBHs show more fluctuation in the south well. The PtSi thickness variations in the nonuniformly doped substrate are suspected to be the reason for these SBH fluctuations. It is expected that they could be minimized by improving PtSi thickness variations.

The hole SBH $\left(\phi_{h}\right)$ was extracted from a fit of previously calibrated MEDICI simulations ${ }^{1}$ on the measured SBFET transfer characteristics. The only fitting parameter was $\phi_{h}$; the other one was specified with the help of XSEM (not shown) and $C-V$ measurements of the SBFETs. In Fig. 2, MEDICI simulation well matches the measured $I_{s}-V_{g}$ of the p-SBFETs with substrate doping levels of $2 \mathrm{e} 17,8 \mathrm{e} 16$, and $1 \mathrm{e} 16 \mathrm{~cm}^{-3} ; \phi_{h}$ is 190,210 , and $240 \mathrm{meV}$, respectively. Note that S/D junction leakage level is reduced in the highly doped transistor.

Both electron and hole SBHs are reduced by $\sim 30$ and $\sim 50 \mathrm{meV}$, respectively, when the doping level rises from 1e16 to $8 \mathrm{e} 16$ and $2 \mathrm{e} 17 \mathrm{~cm}^{-3}$. This symmetrical lowering is believed

${ }^{1}$ MEDICI incorporates a model for calculating transport current through a Schottky contact (thermoionic and field emission) in addition to the usual MOSFET models (such as the concentration-dependant mobility). It also includes a barrier height lowering model (http://www.synopsys.com/products/ tcad/taurus_medici_ds.html).

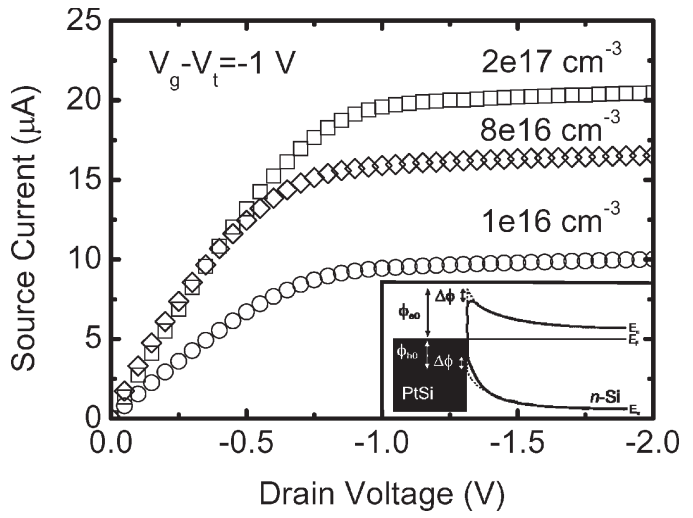

Fig. 3. Measured $I_{s}-V_{d}$ of a 1- $\mu \mathrm{m}$ channel length SBFET on a substrate doping of $1 \mathrm{e} 16 \mathrm{~cm}^{-3}$ (circle), $8 \mathrm{e} 16 \mathrm{~cm}^{-3}$ (rhombus), and $2 \mathrm{e} 17 \mathrm{~cm}^{-3}$ (square). $V_{g}-V_{t}=-1 \mathrm{~V} . V_{t}$ is defined as the voltage corresponding to a current of $10^{-8} \mathrm{~A}$. The inset shows the energy band diagram of the Pt/n-Si junction corrected by the image-force SBH lowering $\Delta \phi$ for the electron barrier height $\phi_{e 0}$ and the hole barrier height $\phi_{h 0}$ [7].

TABLE I

Simulated Electric Field at the PtSi/n-Si Junction, Calculated ELECTRON SBH LOWERING BY [7], AND CALCULATED AND MEASURED ELECTRON SBH DiFFERENCE FROM THE $1 \mathrm{e} 16 \mathrm{~cm}^{-3}$ DOPING LEVEL FOR DOPANT CONCENTRATIONS OF 1e16, 8e16, AND $2 \mathrm{e} 17 \mathrm{~cm}^{-3}$

\begin{tabular}{ccccc}
\hline \hline $\begin{array}{c}\text { Doping } \\
\left(\mathrm{cm}^{-3}\right)\end{array}$ & $\begin{array}{c}E \text { at } \\
\text { interface } \\
(\mathrm{V} / \mathrm{cm})\end{array}$ & $\begin{array}{c}\text { e-SBH lowering } \\
\text { by image-force }\end{array}$ & \multicolumn{2}{c}{ C-SBH difference } \\
\hline $10^{16}$ & $2.10^{4}$ & $15.7 \mathrm{meV}$ & - & - \\
$8.10^{16}$ & $10^{5}$ & $39.3 \mathrm{meV}$ & $\sim 25 \mathrm{meV}$ & $30 \mathrm{meV}$ \\
$2.10^{17}$ & $3.10^{5}$ & $60.9 \mathrm{meV}$ & $\sim 45 \mathrm{meV}$ & $50 \mathrm{meV}$ \\
\hline \hline
\end{tabular}

to be caused by the electrostatic image force attracting the carriers to the metal and therefore reducing their energy close to the junction [7]. As sketched in the inset of Fig. 3, this results in a reduction of the electron and hole SBHs $\left(\phi_{e 0}\right.$ and $\phi_{h 0}$, respectively). According to the image-force lowering model $\left(\Delta_{\phi}=2 \sqrt{q E / 16 \pi \varepsilon_{s}}\right)$ [7], we have calculated the SBH lowering from the electric field at the interface simulated in MEDICI; the data are summarized in Table I. It is shown that the simulations are in excellent agreement with our measured data, enforcing our speculation that the SBH lowering caused by the substrate doping concentration can be attributed to the image-force mechanism.

\section{B. Performance Improvement and Extension to Short-Channel SBFETs}

In Fig. 3, the measured output curves $\left(I_{s}-V_{d}\right)$ of SBFETs (at $V_{g}-V_{t}=-1 \mathrm{~V}$ ) on three different substrate doping levels demonstrate the substantial gain of the drive current associated with the highest doping stemming from the SBH lowering effect. Note that even if a reduction of the hole mobility due to high substrate impurities tends to lower the drive current, the overall effect of increasing substrate doping is to enhance the drive current through the image-force barrier lowering effect.

The substrate doping concentration is also critical for the short-channel SBFET performances on SOI substrate. The MEDICI simulation of the transfer characteristics $\left(I_{s}-V_{g}\right)$ of 100-nm channel length SBFETs on p-/n-SOI substrate with 


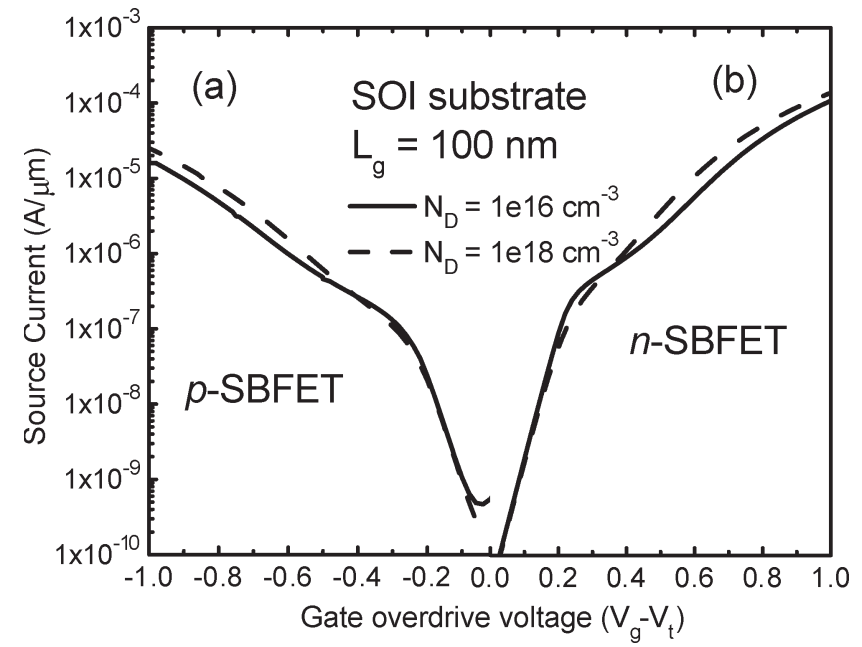

Fig. 4. Simulated transfer characteristics of a 100-nm channel length (a) PtSi and (b) $\mathrm{YbSi}_{1+x}$ SBFET at $V_{d}=-1.1 \mathrm{~V}$ on a SOI substrate with a Si body doping of $1 \mathrm{e} 16 \mathrm{~cm}^{-3}$ (solid line) and $1 \mathrm{e} 18 \mathrm{~cm}^{-3}$ (dashed line). Si body thickness is $10 \mathrm{~nm}$, and silicide thickness is $4 \mathrm{~nm}$.

channel doping of $1 \mathrm{e} 16$ and $1 \mathrm{e} 18 \mathrm{~cm}^{-3}$ is reproduced in Fig. 4 . We observe a $V_{t}$ difference between both devices of $\sim 150 \mathrm{mV}$, which is inherent to the increase of the substrate doping concentration. After offsetting the $V_{t}$, it is observed that the highly doped SBFET exhibits higher drive current due to the enhanced SBH lowering. Note that the increase of $V_{t}$ may be manageable by other process adjustment (such as by the tuning of the metal gate workfunction [10]).

\section{CONCLUSION}

In conclusion, we demonstrate that hole SBH can be lowered through an image-force mechanism by increasing the $\mathrm{n}-\mathrm{Si}$ substrate doping, which leads to a substantial gain of the drive current in the long-channel bulk PtSi S/D p-SBFETs. Numerical simulations show that the channel doping concentration is also beneficial for short-channel SOI n-/p-SBFETs. It would be therefore critical to adjust the well I/I for SOI SBFET to improve its performance.

\section{REFERENCES}

[1] J. Kedzierski, P. Xuan, E. Anderson, J. Bokor, T.-J. King, and C. Hu, "Complementary silicide source/drain thin-body MOSFETs for the $20 \mathrm{~nm}$ gate length regime," in IEDM Tech. Dig., 2000, pp. 57-60.

[2] C. Wang, J. P. Snyder, and J. R. Tucker, "Sub-40 nm PtSi Schottky source/drain metal-oxide-semiconductor field-effect transistors," Appl. Phys. Lett., vol. 74, no. 8, pp. 1174-1176, Feb. 1999.

[3] D. Connelly, C. Faulkner, D. E. Grupp, and J. S. Harris, "A new route to zero-barrier metal source/drain MOSFETs," IEEE Trans. Nanotechnol., vol. 3, no. 1, pp. 98-104, Mar. 2004.

[4] S. Zhu, H. Y. Yu, S. J. Whang, J. H. Chen, and C. Shen et al., "Schottkybarrier S/D MOSFETs with high- $K$ gate dielectrics and metal-gate electrode," IEEE Electron Device Lett., vol. 25, no. 5, pp. 268-270, May 2004.

[5] Q. T. Zhao, U. Breuer, E. Rije, S. Lenk, and S. Mantl, "Tuning of NiSi/Si Schottky barrier heights by sulfur segregation during Ni silicidation," Appl. Phys. Lett., vol. 86, no. 6, p. 062108, Feb. 2005.

[6] J. Knoch, M. Zhang, Q. T. Zhao, S. Lenk, S. Mantl, and J. Appenzeller, "Effective Schottky barrier lowering in silicon-on-insulator Schottkybarrier metal-oxide-semiconductor field-effect transistors using dopant segregation," Appl. Phys. Lett., vol. 87, p. 263505, 2005.

[7] E. H. Rhoderick, Metal-Semiconductor Contacts. Oxford, U.K.: Clarendon, 1978, pp. 35-38.

[8] M. Nishisaka, S. Matsumoto, and T. Asano, "Schottky source/drain SOI MOSFET with shallow doped extension," Jpn. J. Appl. Phys., vol. 42, no. 4B, pp. 2009-2013, Apr. 2003.

[9] H. Norde, "A modified forward $I-V$ plot for Schottky diodes with high series resistance," J. Appl. Phys., vol. 50, no. 7, pp. 5052-5053, Jul. 1979.

[10] R. Singanamalla, H. Y. Yu, G. Pourtois, I. Ferain, K. Anil, S. Kubicek, T. Y. Hoffmann, M. Jurczak, S. Biesemans, and K. De Meyer, "On the impact of TiN film thickness variations on the effective work function of poly-Si/TiN/SiO 2 and poly-Si/TiN/HfSiON gate stacks," IEEE Electron Device Lett., vol. 27, no. 5, pp. 332-334, May 2006. 